\title{
Riboflavin deficiency: early effects on post-weaning development of the duodenum in rats
}

\author{
Catherine A. Yates ${ }^{1}$, Gareth S. Evans ${ }^{1}$ and Hilary J. Powers ${ }^{2 *}$ \\ ${ }^{1}$ The Institute of Child Health, Sheffield Children's Hospital, Sheffield S5 7AU, UK \\ ${ }^{2}$ The Centre for Human Nutrition, The University of Sheffield, The Northern General Hospital, Sheffield S5 7AU, UK
}

(Received 10 October 2000 - Revised 18 May 2001 - Accepted 29 May 2001)

\begin{abstract}
The aim of this present study was to identify the earliest point at which riboflavin deficiency affects post-weaning bowel development in rats. After weaning, eighty Wistar rats were weightmatched as pairs, one animal being fed a normal synthetic diet and the other being fed the same diet but deficient in riboflavin. Body weight, feeding and rates of growth were monitored and eight pairs of animals were taken for analysis at 45, 69, 93, 117 and $141 \mathrm{~h}$. Riboflavin status was monitored by determining the erythrocyte glutathione reductase activation coefficient (EGRAC), and hepatic flavins were measured by a fluorescence assay. Changes to the number and dimensions of villi and crypts in the duodenum were determined, as well as crypt division (bifurcation) and the DNA synthesis index of the crypt epithelium by bromodeoxyuridine (BrdU) labelling. Riboflavin deficiency was established in the experimental rats, as demonstrated by a significant increase in EGRAC after $45 \mathrm{~h}(P<0.001)$ and decreased liver flavins after $96 \mathrm{~h}$ $(P<0 \cdot 001)$. After $96 \mathrm{~h}$ a significant increase in the size and cellularity of the crypts $(P<0 \cdot 001 \mathrm{in}$ both cases) was seen in these riboflavin-deficient animals, with a decreased incidence of bifurcating crypts and of BrdU-labelled cells. No changes to villus number or size were observed. The present study has demonstrated that developmental changes to the duodenal crypt arise shortly after circulating riboflavin measurements show evidence of deficiency. These changes primarily affect cell proliferation and crypt bifurcation, and precede long-term changes such as the reduction of villus number.
\end{abstract}

Riboflavin deficiency: Duodenum: Proliferation: Morphogenesis

The maturation of gastrointestinal function at the time of weaning is regulated in part by changes to the composition of the diet. Animal studies have identified qualitative and quantitative changes to the gastrointestinal tract following alterations in diet at this time. For example, weaning rats fed a diet low in carbohydrate but high in fat have a reduced expression of the brush-border enzyme sucrase, whereas the expression increases in those animals fed a diet high in carbohydrates but low in fat (Henning \& Guerin, 1981). In lambs the transition from milk to grass results in a reduction in the concentration of monosaccharides in the lumen. As a consequence there is a very rapid reduction in the expression of the $\mathrm{Na}^{+} /$glucose co-transporter, but D-glucose and other glucose analogues infused into the lumen can rapidly restore expression of the $\mathrm{Na}^{+}$/glucose co-transporter (Dyer et al. 1997).

In rats, weaning is associated with a transient increase in the crypt cell proliferation in the small intestine and a decreased expression of brush-border lactase. However, when fed a diet of reduced protein content, no increase in epithelial proliferation occurred and lactase continued to be expressed at preweaning levels (Buts \& Nyakabasa, 1985). In rats fed an Fe-deficient diet post-weaning a significantly reduced activity of sucrase, lactase and maltase, and synthesis of secretory component were observed (Lanzkowsky et al. 1982; Buts \& DeMeyer, 1984). Alteration to the fatty acid composition of the weaning diet was also found to change the transport of galactose, hexose and lipids (Thomson et al. 1989).

We have reported that dietary deficiency of riboflavin for a period as short as $7 \mathrm{~d}$ following weaning results in morphological and cell kinetic changes to the gastrointestinal tract of weaning rats (Williams et al. 1995, 1996a, b). After $7 \mathrm{~d}$ of riboflavin depletion crypt hypertrophy was evident, and there were fewer villi per unit area of mucosa compared with controls. After more prolonged depletion

\footnotetext{
Abbreviations: BrdU, bromodeoxyuridine; DBA, Dolichos biflorus agglutinin; EGRAC, erythrocyte glutathione reductase activation coefficient.

* Corresponding author: Dr. H. J. Powers, fax +44 114261 0112, email h.j.powers@sheffield.ac.uk
} 
villus hypertrophy was observed and may have represented an adaptation response to this deficiency. In this current study, cell kinetic and morphological changes to the duodenal epithelium were measured $2-6 \mathrm{~d}$ following weaning in rats fed either a normal diet, or a diet deficient in riboflavin. The aim of the present study was to identify the earliest point at which riboflavin deficiency affects post-weaning duodenal development in the rat.

\section{Materials and methods}

\section{Materials}

All buffer salts, chemicals and histological dyes were purchased from Sigma Chemical Ltd (Poole, Dorset, UK) and from BDH Gurr (Poole, Dorset, UK). The primary antibody for bromodeoxyuridine (BrdU) immunostaining was purchased from Dako Ltd (Ely, Cambs., UK) and the secondary antibodies and detection reagents from Vector Laboratories (Peterborough, Cambs., UK). Reagents for measuring glutathione reductase and liver flavins were purchased from Sigma Chemical Ltd. All dietary components were purchased from Sigma Chemical Ltd, with the exception of arachis oil (Hillcross Pharmaceuticals Ltd, Burnley, UK), Briggs salt mixture (Seaford Laboratories, Seaford, East Sussex, UK) and acid-washed casein (MRC Dunn Unit, Cambridge, UK).

\section{Animals}

Wistar rats were bred in pathogen-free isolated conditions and were housed in wire-bottomed cages to prevent coprophagy. They were permitted free access to tap water and maintained under standard laboratory conditions with a $12 \mathrm{~h}$ light-dark cycle, a mean temperature of $21^{\circ} \mathrm{C}$ and a mean humidity of $45 \%$. All procedures were carried out in compliance with the current UK Home Office Regulations and under project license PPL 50/1309.

\section{Dietary protocol and weight matching}

Eighty female weaning Wistar rats weighing between 40 and $65 \mathrm{~g}$ were used for the study. Animals were weaned from their mothers on postnatal day 21. On arrival rats were paired by weight and allocated to one of two dietary groups. One rat from each pair was assigned to the riboflavindeficient group and fed a semi-synthetic diet prepared in-house containing no added riboflavin. The depleted diet contained $(\mathrm{g} / \mathrm{kg})$ : 30 arachis oil, 700 sucrose, 200 casein $0 \cdot 24$ riboflavin-free vitamin mixture, 50 Briggs salt mixture. The residual content of riboflavin in this diet was determined as $0.52 \mathrm{mg} / \mathrm{kg}$ diet. This is sufficient to allow growth to continue and to prevent overt clinical signs of deficiency. The other rat of the pair received a control diet consisting of the same semi-synthetic diet but further supplemented with $15 \mathrm{mg}$ riboflavin/ $/ \mathrm{kg}$.

The inanition effects of a diet deficient in riboflavin are well known (Parsons \& Dias, 1991; Williams et al. 1996a). To allow study of the effects of riboflavin deficiency per se on gastrointestinal development, which is also influenced by body weight (Younoszai \& Ranshaw, 1974), weight matching was carried out. The animals fed the riboflavindeficient diet were fed ad libitum throughout the study, but the control animals were fed an amount of diet sufficient to maintain their weight equal to that of the riboflavin-deficient partner $( \pm 10 \%)$. To achieve matching the rats were weighed and fed daily between 09.00 and 10.00 hours.

\section{Study design}

The rats were maintained on their respective diets for 45, 69, 93, 117 or $141 \mathrm{~h}$ from weaning to death. These times reflect the arrival of the animals from the breeding colony in the afternoon to the point at which the animals were killed. At each time point, eight weight-matched pairs of animals were killed by chloroform inhalation.

\section{Tissue sampling}

At $60 \mathrm{~min}$ before exanguination each animal received an intraperitoneal injection of $0.5 \mathrm{ml} \mathrm{BrdU}(0.4 \mathrm{mg} / \mathrm{g}$ body weight prepared in isotonic saline $(9 \mathrm{~g} \mathrm{NaCl} / 1))$. After exanguination, the thorax was opened and blood was collected by cardiac puncture. Erythrocytes were separated, washed in isotonic saline and stored in distilled water at a ratio of $1: 3(\mathrm{v} / \mathrm{v})$ at $-20^{\circ} \mathrm{C}$. The liver was also removed, rinsed in saline, weighed and frozen at $-20^{\circ} \mathrm{C}$.

\section{Determination of erythrocyte glutathione reductase activation coefficient}

The activity of erythrocyte glutathione reductase was measured using the method described by Glatzle et al. (1970) and modified (Powers et al. 1983) for use on the Cobas Bio Autoanalyser (Roche Diagnostics, Welwyn Garden City, Herts., UK). The activity of the enzyme was measured in the venous haemolysate as activity with: activity without exogenous FAD. An erythrocyte glutathione reductase activation coefficient (EGRAC) greater than 1.3 was taken to indicate unsaturation of the enzyme with FAD and evidence of biochemical deficiency (Tillotson \& Baker, 1972).

\section{Liver flavins}

Liver flavins were measured using a fluorimetric assay according to principles described by Bessey et al. (1949). The liver samples were homogenized, the flavins extracted, and the fluorescence measured using a Perkin Elmer 3000 (Boston, MA, USA) fluorescence spectrometer (Perkin Elmer, at $450 \mathrm{~nm}$ excitation and $510 \mathrm{~nm}$ emission wavelengths). Background fluorescence was measured by the addition of sodium dithionite to reduce riboflavin to the non-fluorescent dihydroriboflavin. Total flavins were calculated after a $37^{\circ} \mathrm{C}$ overnight incubation. The two sets of fluorescence values were then used to calculate concentrations of FAD, FMN and riboflavin, and total liver flavins as $\mu \mathrm{g} / \mathrm{g}$ liver wet weight. As FMN and riboflavin fluoresce with the same intensity it is not possible to separate their relative contributions to the overall fluorescence, hence they were measured together. 


\section{Histology}

The small intestine was carefully dissected, rinsed in saline and its length recorded. Two $10 \mathrm{~mm}$ segments were cut from the pyloric sphincter representing the duodenum. The first segment was fixed in $4 \%(\mathrm{v} / \mathrm{v})$ formaldehyde in PBS $(\mathrm{pH}$ 7.4) cut into small transverse segments and bundled in $3 \mathrm{M}$ tape (Potten \& Hendry, 1985). The tissue bundle was then dehydrated, cleared in xylene, embedded in Paraplast wax and $5 \mu \mathrm{m}$ thick serial sections cut on a rotary microtome (Anglia Scientific, Cambridge, UK). The histologist was 'blind' to the identity of samples for all histological analyses.

\section{Scanning electron microscopy and counts of villus number}

Sections of intestine were opened longitudinally, pinned out with the luminal surface facing up, and fixed in $1 \%(\mathrm{v} / \mathrm{v})$ glutaraldehyde in $0.1 \mathrm{M}$-sodium cacodylate buffer overnight. The tissue was then washed, treated with $1 \%(\mathrm{v} / \mathrm{v})$ $\mathrm{OsO}_{4}$, dehydrated, critically point dried (Polaron 3000, East Grinsted, UK), mounted on Al stubs, and sputter-coated in Au (Edwards S150 Edwards High Vacuum International, Crawley, W. Sussex, UK). Electron micrographs of the luminal surface were taken at $80 \times$ magnification on a Philips SEM501 scanning microscope (Philips, FEI Company Electron Optics, Eindhoven, The Netherlands). An acetate grid of defined area was placed over each micrograph and villi number per unit area determined. Five randomly-placed grids were counted on each micrograph per rat. The number of villi per unit area was then expressed as mean villi $/ \mathrm{mm}^{2}$.

\section{Counts of crypt bifurcation}

Bundles of intestine were prepared as described previously. These were sectioned transversely $(5 \mu \mathrm{m})$ and stained with haematoxylin and eosin to determine the incidence of crypt bifurcation. Four non-serial sections from each tissue block were analysed per animal, and the total number of crypts and number of crypts with clear evidence of splitting at their base (bifurcation), were counted around the circumfirence. Only those crypts in which a plane of division extended for several cell positions upwards from the Paneth cells were counted. It is likely that this method underestimates the number of bifurcating events, since only those crypts dividing perpendicular to the plane of sectioning will be observed. However, these considerations apply equally to control and riboflavin-deficient groups. Bifurcation was expressed as a percentage of total crypts per section.

\section{Crypt and villus dimensions}

The measurements were made with four non-serial $5 \mu \mathrm{m}$ transverse sections from each animal. The sections were stained with haematoxylin and eosin, and viewed and measured with an image analysis system (Image Manager, PC; Sight Systems, Worthing, West Sussex, UK) calibrated (in $\mu \mathrm{m}$ ) using an ocular magnification of $10 \times$. A total of forty crypts and twenty villi were measured from each animal. To measure the crypt height only those crypts in which the lumen was present from the base to the mouth of the crypt (i.e. centrally sectioned) were measured. Villus height was measured where the lamina propria core was present from the base to the tip of the villus.

\section{Immunostaining for bromodeoxyuridine}

This procedure was carried out according to the method described by Wynford-Thomas \& Williams (1986). Sections were denatured in $1 \mathrm{M}-\mathrm{HCl}$ for $3 \mathrm{~min}$ at $60^{\circ} \mathrm{C}$, neutralized in $0.2 \mathrm{M}$-boric acid and $0.05 \mathrm{M}$-disodium tetraborate $(\mathrm{pH} \mathrm{8.4)}$, washed in PBS and stained with a mouse monoclonal anti-BrdU antibody (Dako Labs, Glostrup, Denmark) at 1/750 dilution. The immunostain was detected by avidin-biotin peroxidase ABC kit (Vectastain; Vector Laboratories) with diaminobenzidine substrate. The sections were counterstained in $1 \mu \mathrm{g}$ Hoechst 33342 dye/ml, dehydrated, cleared and mounted in DPX (BDH Gurr). For each animal the total cell number and number of labelled cells per crypt (only centrally-sectioned crypts were chosen) were counted in four non-serial sections. The labelling index was then expressed as \% BrdU-labelled crypt cells.

\section{Statistical analysis}

A two-way ANOVA followed by a Scheffe test was used to investigate effects of time and diet on all independent variables that were normally distributed, which were final body weight, food consumption, g weight gain/g diet, liver flavin concentrations, crypt depth, incidence of crypt bifurcation, villus number, villus length and BrdU-labelling index. For EGRAC, which was not normally distributed, the Kruskall-Wallis ANOVA was applied, followed by the Mann-Whitney $U$ test.

\section{Results}

\section{Riboflavin status and food consumption}

Erythrocyte glutathione reductase activation coefficient. The measurement of EGRAC established that in the groups

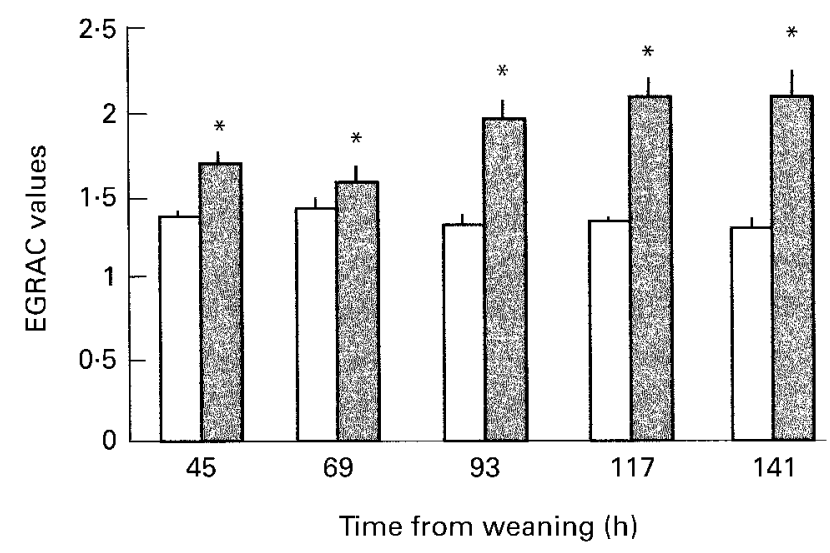

Fig. 1. Measurement of erythrocyte glutathione reductase activation coefficient (EGRAC) in rats maintained on a normal $(\square)$ or a riboflavin-depleted ( $\square$ ) diet from weaning for $45,69,93,117$ or $141 \mathrm{~h}$. Values are means with their standard errors represented by vertical bars for eight weight-matched pairs of animals. Mean values were significantly different from those for the control group (KruskallWallis and Mann-Whitney $U$ test): ${ }^{\star} P<0 \cdot 05$. For details of diets and procedures, see p. 594. 
Table 1. Liver flavin concentrations in rats fed either a riboflavin-deficient (RD) or control (C) diet from weaning (Means with their standard errors for eight weight-matched pairs of animals)

\begin{tabular}{|c|c|c|c|c|c|c|c|c|c|c|c|c|}
\hline \multirow[b]{3}{*}{ Time on diet (h) } & \multicolumn{4}{|c|}{ Liver FAD ( $\mu \mathrm{g} / \mathrm{g}$ wet wt) } & \multicolumn{4}{|c|}{ Liver FMN + riboflavin ( $\mu \mathrm{g} / \mathrm{g}$ wet wt) } & \multicolumn{4}{|c|}{ Total liver flavins ( $\mu \mathrm{g} / \mathrm{g}$ wet $w \mathrm{t}$ ) } \\
\hline & \multicolumn{2}{|c|}{$\mathrm{C}$} & \multicolumn{2}{|c|}{$\mathrm{RD}$} & \multicolumn{2}{|c|}{ C } & \multicolumn{2}{|c|}{$\mathrm{RD}$} & \multicolumn{2}{|c|}{ C } & \multicolumn{2}{|c|}{$\mathrm{RD}$} \\
\hline & Mean & SEM & Mean & SEM & Mean & SEM & Mean & SEM & Mean & SEM & Mean & SEM \\
\hline 45 & $18 \cdot 9$ & $1 \cdot 20$ & $15 \cdot 03^{*}$ & 0.83 & 3.88 & 1.04 & $2 \cdot 96$ & 0.42 & $22 \cdot 83$ & $1 \cdot 26$ & $18 \cdot 04^{*}$ & 0.96 \\
\hline 69 & 14.72 & 0.96 & $12 \cdot 19$ & 1.04 & $4 \cdot 32$ & 0.50 & $3 \cdot 02^{\star}$ & 0.24 & $19 \cdot 06$ & 0.81 & $16 \cdot 02$ & 1.44 \\
\hline 93 & $17 \cdot 73$ & 0.52 & $13 \cdot 61^{\star \star}$ & $0 \cdot 76$ & 4.56 & 0.26 & $3 \cdot 13^{\star *}$ & 0.15 & 22.09 & 0.91 & $16 \cdot 66^{\star \star \star}$ & 0.75 \\
\hline 117 & 19.09 & 0.49 & $13 \cdot 34^{\star \star \star}$ & 0.52 & 4.84 & 0.23 & $2 \cdot 97^{\star \star *}$ & 0.11 & $23 \cdot 22$ & 0.66 & $16 \cdot 17^{\star \star \star}$ & 0.58 \\
\hline 141 & 24.77 & 0.92 & $15 \cdot 28^{\star \star *}$ & 0.62 & 7.90 & 0.39 & $4 \cdot 46^{* * *}$ & 0.25 & $32 \cdot 71$ & $1 \cdot 11$ & $19 \cdot 73^{\star \star \star}$ & 0.72 \\
\hline
\end{tabular}

Mean values were significantly different from those for the controls (ANOVA followed by scheffe test): ${ }^{\star} P<0 \cdot 05,{ }^{\star \star} P<0 \cdot 01,{ }^{\star \star \star} P<0 \cdot 001$.

†For details of diets and procedures, see p. 594.

fed a riboflavin-deficient diet there was a progressive increase in the activation coefficient for the enzyme, consistent with depletion of riboflavin (Fig. 1). By $45 \mathrm{~h}$ the difference between the groups had reached significance $(P<0.01)$ and remained so for the duration of the experiment.

Liver flavin concentrations. A decrease in hepatic concentrations of FAD, FMN and riboflavin, as well as total liver flavins, was observed in the animals fed the riboflavin-deficient diet. The decrease in FAD had reached significance by $45 \mathrm{~h}$ (Table 1 ), and by $141 \mathrm{~h}$ had fallen to only $60 \%$ of the levels found in the livers of control animals $(P<0 \cdot 0001)$.

Growth and food consumption. The food consumption was not significantly influenced by time on the diet (Table 2). Consistent with the weight-matching regimen there was no overall difference in the mean body weight, or increase in body weight between the control and riboflavindeficient diet groups, except at 93 and $117 \mathrm{~h}$ where the animals fed a deficient diet weighed slightly less (7.4\% and $8.1 \%$ respectively). Weight gain (g/g diet) was lower in the animals on the riboflavin-deficient diet after $117 \mathrm{~h}$ and remained low at $141 \mathrm{~h}$.

\section{Gastrointestinal morphology and cytokinetics}

Villi number and length. No effect of time, or diet, on the unit density (villi $/ \mathrm{mm}^{2}$ ) or height of the villi was observed (Table 3).
Crypt depth and bifurcation. An increase in the height of the crypts in animals fed the riboflavin-deficient diet was evident after $69 \mathrm{~h}$ (Fig. 2), and this difference was maintained throughout the experiment $(P<0 \cdot 001)$. Crypt bifurcation in riboflavin-deficient animals failed to increase with time from weaning, an effect which was seen in control animals (Fig. 3). From $93 \mathrm{~h}$ the proportion of crypts undergoing crypt bifurcation was significantly lower in riboflavin-deficient animals $(P<0 \cdot 01)$.

Crypt cellularity. No increase in crypt cellularity was observed in the control group (Fig. 4), in contrast with animals fed the riboflavin-deficient diet. This increase was significant after $69 \mathrm{~h}(P<0 \cdot 001)$.

Crypt cell proliferation. In contrast to control animals the proliferative BrdU index fell from $69 \mathrm{~h}$ in the animals fed the riboflavin-deficient diet, and values remained significantly lower than those for the control animals at all time points thereafter $(P<0 \cdot 001$; Fig. 5).

\section{Discussion}

The present study has demonstrated in the post-weaning rat that morphological and kinetic changes to the duodenal epithelium can be observed after $2 \mathrm{~d}$ in those animals fed a riboflavin-deficient diet. The critical change observed in the present study affected the multiplication of the intestinal crypts that contain the epithelial stem cells, transit amplifying cells and differentiating enterocytes, goblet, Paneth and enteroendocrine cells. In the rats fed the

Table 2. Growth and food consumption of rats fed either a riboflavin-deficient (RD) or a control (C) diet from weaning $\dagger$ (Mean with their standard errors for eight weight-matched pairs of animals, except at $0 \mathrm{~h}$, where values are for forty animals)

\begin{tabular}{|c|c|c|c|c|c|c|c|c|c|c|c|c|}
\hline \multirow[b]{3}{*}{ Time on diet (h) } & \multicolumn{4}{|c|}{ Body wt at kill (g) } & \multicolumn{4}{|c|}{ Food consumed $(\mathrm{g} / \mathrm{d})$} & \multicolumn{4}{|c|}{ Wt gain (g/g diet) } \\
\hline & \multicolumn{2}{|c|}{$\mathrm{C}$} & \multicolumn{2}{|c|}{$\mathrm{RD}$} & \multicolumn{2}{|c|}{$\mathrm{C}$} & \multicolumn{2}{|c|}{$\mathrm{RD}$} & \multicolumn{2}{|c|}{$\mathrm{C}$} & \multicolumn{2}{|c|}{$\mathrm{RD}$} \\
\hline & Mean & SEM & Mean & SEM & Mean & SEM & Mean & SEM & Mean & SEM & Mean & SEM \\
\hline 0 & 48.93 & $1 \cdot 16$ & $47 \cdot 24$ & $1 \cdot 17$ & - & - & - & - & - & - & - & - \\
\hline 45 & 55.04 & 1.89 & 53.77 & 1.88 & 11.84 & 0.60 & 13.02 & 0.45 & 0.19 & 0.02 & 0.14 & 0.02 \\
\hline 69 & 64.44 & 2.49 & $61 \cdot 14$ & $5 \cdot 62$ & - & - & $12 \cdot 63$ & 0.82 & 0.19 & 0.02 & 0.17 & 0.01 \\
\hline 93 & $50 \cdot 79$ & 0.91 & $47.06^{*}$ & 0.85 & 13.81 & 0.71 & 11.94 & 0.97 & 0.17 & 0.01 & 0.15 & 0.01 \\
\hline 117 & 62.02 & 0.91 & $56 \cdot 98^{*}$ & 0.89 & $14 \cdot 10$ & 0.54 & $14 \cdot 34$ & 0.72 & 0.22 & 0.01 & $0.17^{*}$ & 0.01 \\
\hline 141 & $62 \cdot 19$ & 2.20 & 56.92 & 2.28 & $15 \cdot 64$ & 1.22 & $17 \cdot 32$ & 0.42 & 0.19 & 0.01 & $0.13^{*}$ & 0.01 \\
\hline
\end{tabular}

Mean values were significantly different from those for the controls (ANOVA followed by Scheffe test): ${ }^{\star} P<0.05$.

†For details of diets and procedures, see p. 594. 
Table 3. Effect of feeding a riboflavin-deficient $(R D)$ or control $(C)$ diet to rats from weaning on the length of villi and density of villi*

(Means with their standard errors for eight weight-matched pairs of animals)

\begin{tabular}{|c|c|c|c|c|c|c|c|c|}
\hline \multirow[b]{3}{*}{ Time on diet (h) } & \multicolumn{4}{|c|}{ Villus length $(\mu \mathrm{m})$} & \multicolumn{4}{|c|}{ Villus density $(\mu \mathrm{m})$} \\
\hline & \multicolumn{2}{|c|}{ C } & \multicolumn{2}{|c|}{$\mathrm{RD}$} & \multicolumn{2}{|c|}{$\mathrm{C}$} & \multicolumn{2}{|c|}{$\mathrm{RD}$} \\
\hline & Mean & $\overline{\text { SEM }}$ & Mean & $\overline{\text { SEM }}$ & Mean & SEM & Mean & SEM \\
\hline 45 & 573.6 & $13 \cdot 0$ & 561.6 & $13 \cdot 6$ & NA & & NA & \\
\hline 69 & 583.8 & 11.2 & 613.7 & $10 \cdot 7$ & NA & & NA & \\
\hline 93 & $590 \cdot 4$ & $15 \cdot 3$ & 629.3 & $9 \cdot 2$ & 57.0 & 1.7 & 57.5 & 3.3 \\
\hline 117 & $599 \cdot 4$ & $10 \cdot 2$ & 584.0 & $29 \cdot 2$ & 58.7 & $2 \cdot 7$ & $54 \cdot 3$ & 3.0 \\
\hline 141 & $622 \cdot 3$ & $18 \cdot 8$ & $599 \cdot 3$ & $12 \cdot 3$ & $62 \cdot 2$ & $2 \cdot 1$ & $61 \cdot 7$ & 2.0 \\
\hline
\end{tabular}

$\mathrm{NA}$, values for the 45 and $69 \mathrm{~h}$ villus density were not obtained due to problems with tissue handling.

${ }^{*}$ For details of diets and procedures, see p. 594.

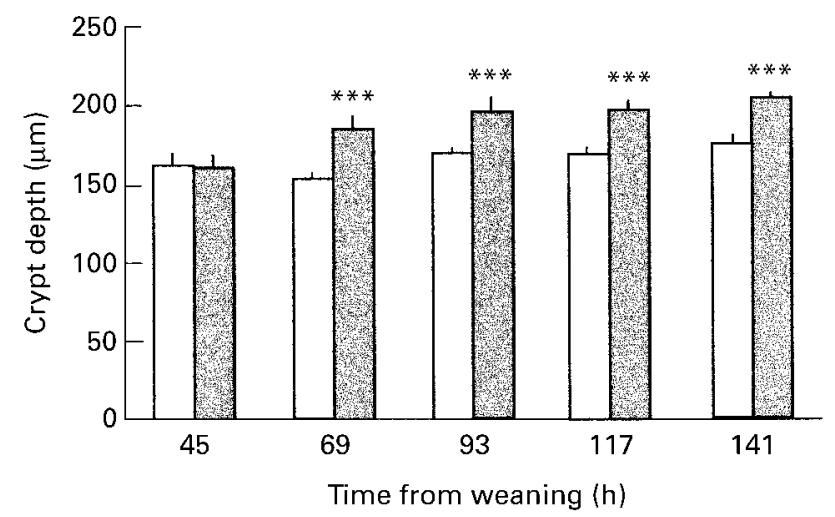

Fig. 2. Measurement of crypt depth in rats maintained on a normal $(\square)$ or a riboflavin-depleted (ם) diet from weaning for 45, 69, 93, 117 or $141 \mathrm{~h}$. Values are means with their standard errors represented by vertical bars for eight weight-matched pairs of animals. For each animal the depth of twenty centrally-sectioned crypts were measured. Mean values were significantly different from those for the control group (ANOVA and Scheffe test): ${ }^{* * *} P<0.001$. For details of diets and procedures, see p. 594.

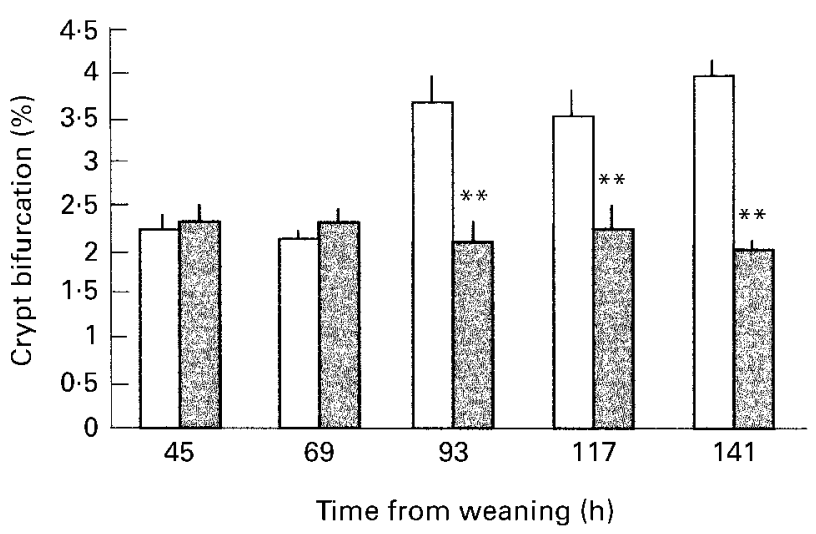

Fig. 3. Measurement of crypt bifurcation in rats maintained on a normal $(\square)$ or a riboflavin-depleted ( $\square$ ) diet from weaning for 45, 69, 93,117 or $141 \mathrm{~h}$. Values are means with their standard errors represented by vertical bars for eight weight-matched pairs of animals. For each animal the incidence of bifurcating crypts was determined in four non-serial sections for each animal. Mean values were significantly different from those for the control group (ANOVA and Scheffe test): ${ }^{\star *}(P<0 \cdot 01)$. For details of diets and procedures, see p. 594. riboflavin-deficient diet crypt depth and cellularity increased, but the BrdU-labelling index and proportion of crypts bifurcating decreased. The present study has added to existing evidence that riboflavin deficiency post-weaning can influence the development of the duodenum in rats. No change to the villus population was observed in this present study, suggesting that the crypt population is the target of the earliest effects of riboflavin deficiency. This finding is consistent with those of other studies in which changing levels of hormones, or diet, were shown to impact on the crypt stem cells. Our previous studies (Williams et al. 1995, $1996 a, b)$ examined the effects of this deficiency for longer periods after weaning, and showed that riboflavin deficiency restricts the expansion of the duodenal villus number. The present study has demonstrated that these changes to the villus population probably follow as a consequence of earlier effects on the crypt epithelium.

These changes to the crypts are significant in the context of bowel development, but also in the process by which the stem cells are regulated. It has been suggested that the

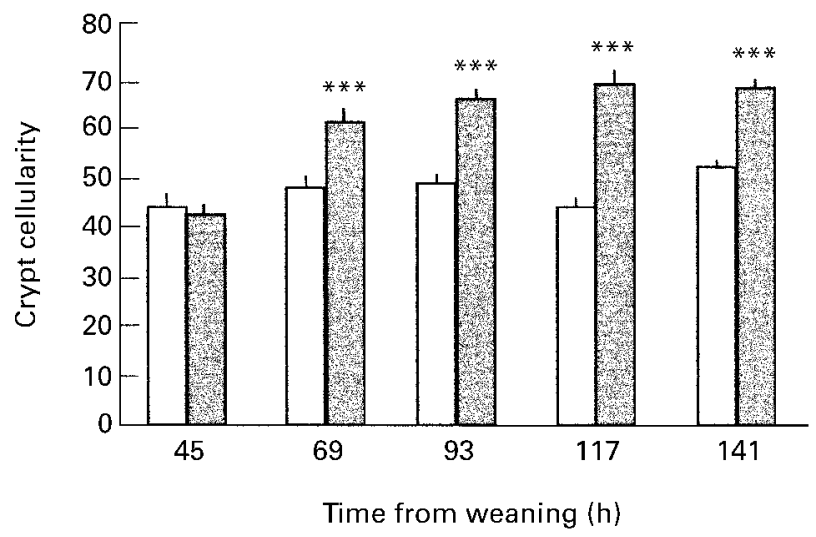

Fig. 4. Measurement of relative crypt cellularity in rats maintained on a normal $(\square)$ or a riboflavin-depleted ( $\square$ ) diet from weaning for $45,69,93,117$ or $141 \mathrm{~h}$. Values are means with their standard errors represented by vertical bars for eight weight-matched pairs of animals. For each animal the number of cells from the base to the neck of centrally-sectioned crypts were determined in twenty crypts for each animal. Mean values were significantly different from those for the control group (ANOVA and Scheffe test): ${ }^{\star * \star} P<0.001$. 


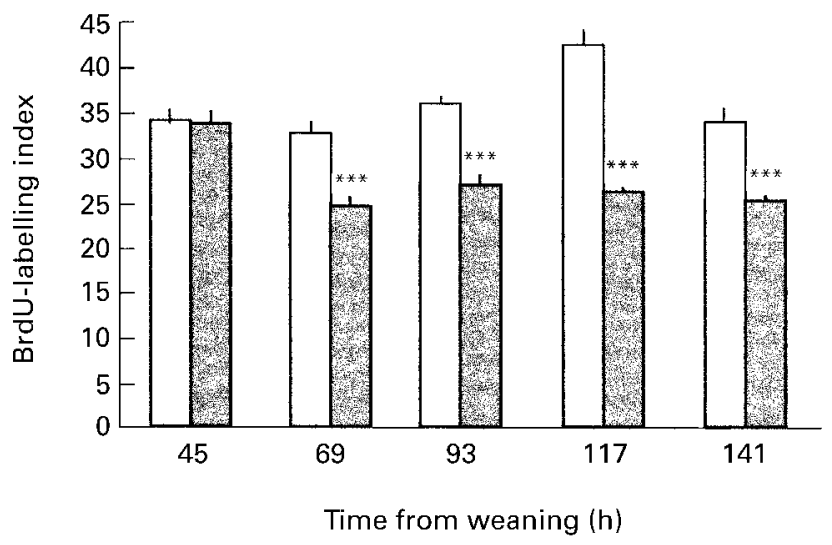

Fig. 5. Measurement of the bromodeoxyuridine (BrdU) proliferativelabelling index by immunohistochemistry in rats maintained on a normal $(\square)$ or a riboflavin-depleted ( $\square$ ) diet from weaning for 45,69 , 93,117 or $141 \mathrm{~h}$. Values are means with their standard errors represented by vertical bars for eight weight-matched pairs of animals. For each animal the total number of crypt cells and of BrdU-positive cells in twenty centrally-sectioned crypts was determined in four non-serial sections for each animal. Mean values were significantly different from those for the control group (ANOVA and Scheffe test): ${ }^{* \star} P<0.001$.

regulation of crypt cellularity, size and bifurcation are tightly regulated and related to the control of the stem cell population (Totafurno et al. 1987; Potten \& Loeffler, 1990). Studies by Ponder et al. (1985) have used mouse aggregation chimeras between strains expressing Dolichos biflorus agglutinin (DBA) lectin-binding sites and strains that do not. They observed during postnatal bowel development that crypts were polyclonal structures containing a mixture of DBA-positive and -negative cells. Later in development these crypts became monoclonal, either fully expressing or not expressing this marker. This finding suggested a process by which one type of cell, either DBApositive or -negative, was removed, resulting in crypts containing a homogeneous population of cells. It was also observed that patches of DBA-negative crypts appeared, suggesting that they had expanded by a process of crypt bifurcation. The control of bifurcation may also involve a feedback mechanism such that crypts normally divide when their cellularity reaches a certain upper size limit (Totafurno et al. 1987).

Riboflavin deficiency post-weaning did not completely inhibit this process, but the post-weaning increase in crypt bifurcation seen in the control animals was not observed in those fed the riboflavin-deficient diet. The increase in crypt bifurcation in the control animals was consistent with other measures of proliferation and growth, and probably stimulated by physiological drive on the change to a solid diet. These changes included an increase in the proportion of proliferating cells (see Fig. 5) but not of crypt depth (see Fig. 2). Thus, in the normal rat as crypt proliferative activity increased, crypt bifurcation also increased, maintaining the crypt cellularity and depth. In contrast, in those animals fed the riboflavin-deficient diet there was no post-weaning increase in bifurcation, resulting in an increased crypt cellularity and depth. The depths of the crypts measured in the control animals were consistent with those of similarly-aged animals (Goodlad \& Wright, 1990), but the increased crypt depths in the riboflavindeficient group exceeded these measurements. It might be expected that this increase in crypt cellularity would be matched by a faster migration of cells onto the villi. Whilst this factor was not examined in the present study, rats kept deficient for longer periods demonstrated an increase in the size of crypts and villi, and in the crypt cell production rate. This finding suggests that there is an altered kinetic balance in the duodenum of riboflavin-deficient animals. These present results are consistent with evidence that the precocious expression of brush-border hydrolyses, induced by administration of a hydrocortisone injection to 9-d-old rats, requires an effect on the proliferative precursor crypt cell population (Henning et al. 1975).

Whilst no change to the villus population was seen in this present study, rats made riboflavin deficient for longer periods following weaning have a reduced density of villi compared with their weight-matched controls (Williams et al. 1995). In addition, the villi and crypts were enlarged compared with the controls. This developmental change was not reversible (Williams et al. 1996a), suggesting the crypts and villi became larger as a compensatory mechanism to increase the mucosal absorptive area.

Post-weaning increases in crypt and villus number have been reported and are consistent with the increasing size of the bowel during this period. However, some researchers have argued that the number of villi is laid down in late fetal and early postnatal development, and is then fixed after this point (Clarke, 1972; Forrester, 1972). In these other studies villi were counted along the entire small intestine and by different techniques. We have used scanning electron microscopy preparations so that the density of intact villi was directly determined, avoiding the stereological problems associated with counting villi in thin sections.

At the beginning of the present study animals were carefully weight-matched in pairs, and the feeding regimen of control animals was continually modified to match consumption by the riboflavin-deficient animal (see Table 1). Nevertheless, the rate of weight gain was decreased in those rats fed the riboflavin-deficient diet, consistent with the requirement for this vitamin in the utilization of energy from food (Olpin \& Bates, 1982a, $b$ ). Using this experimental design it was possible to show that riboflavin deficiency was responsible for the developmental changes, and not other factors such as altered food consumption or body weight. Further evidence was the significant increase in EGRAC values after $48 \mathrm{~h}(P<0 \cdot 05)$, which was followed $24 \mathrm{~h}$ later by the first detectable changes to the crypts (see Fig. 2). Whilst the EGRAC values for both groups of animals were greater than 1.3 (i.e. conventionally regarded as normal; Tillotson \& Baker, 1972) other researchers have demonstrated that EGRAC values may reach 1.5 even in rats fed riboflavin-replete diets (Powers et al. 1983, 1991; Duerden \& Bates, 1985). However, consistent with the establishment of a riboflavin deficiency, reduced liver flavin levels (the marker of long-term deficiency), were observed after $96 \mathrm{~h}$.

Whether the effect of riboflavin deficiency on crypt bifurcation is direct, or indirect, the present study has demonstrated that developmental changes arise first in the 
crypts shortly after measures of circulating riboflavin status are altered. Further studies have now shown that if rats are kept riboflavin replete by intramuscular injection of FMN, changes to the crypts still occur if the animals are fed a diet deficient in riboflavin (CA Yates, GS Evans and HJ Powers, unpublished results). This finding suggests that a crypt luminal-sensing mechanism may be involved in the response to dietary riboflavin deficiency.

Riboflavin deficiency is endemic in many regions of the world (Bamji, 1981; Powers et al. 1985; Brun et al. 1990). Exposure to a riboflavin-deficient environment in utero, and postnatally, may compromise human duodenal development through similar mechanisms to those proposed here.

\section{Acknowledgement}

Acid-washed casein was a gift from the MRC Dunn Unit (Cambridge, UK).

\section{References}

Bamji MS (1981) Enzymatic riboflavin and pyridoxine deficiencies in young Indian women suffering from different grades of glossitis. Nutrition Reports International 24, 649-658.

Bessey OA, Lowry OH \& Love RH (1949) The fluorimetric measurement of the nucleotides of riboflavin and their concentrations in tissues. Journal of Biological Chemistry $\mathbf{1 8 0}$, $755-769$.

Brun TA, Chen J, Campbell TC, Boreham J, Feng Z, Parpia B, Shen TF \& Li M (1990) Urinary riboflavin excretion after a load test in rural China as a measure of possible riboflavin deficiency. European Journal of Clinical Nutrition 44, 195-206.

Buts JP \& DeMeyer R (1984) Intestinal development in the suckling rat: effects of weaning, diet composition, and glucocorticoids on thymidine kinase activity and DNA synthesis. Pediatric Research 18, 145-150.

Buts JP \& Nyakabasa M (1985) Role of dietary protein adaptation at weaning in the development of the rat gastrointestinal tract. Pediatric Research 19, 857-862.

Clarke RM (1972) The effect of growth and fasting on the number of villi and crypts in the small intestine of the albino rat. Journal of Anatomy 112, 27-33.

Duerden JM \& Bates CJ (1985) Effect of riboflavin deficiency on reproductive performance and on biochemical indices of riboflavin status in rats. British Journal of Nutrition 53, 97-105.

Dyer J, Barker PJ \& Shirazi-Beechey SP (1997) Nutrient regulation of the intestinal $\mathrm{Na}+$ /glucose co-transporter (SGLT1) gene expression. Biochemical and Biophysical Research Communications 230, 624-629.

Forrester JM (1972) The number of villi in the rats' jejunum and ileum: Effect of normal growth, partial enterectomy, and tube feeding. Journal of Anatomy 111, 283-291.

Glatzle D, Korner WF, Christellens S \& Wiss O (1970) Method for the detection of a biochemical riboflavin deficiency. Stimulation of $\mathrm{NADPH}_{2}$-dependent glutathione reductase from human erythrocytes by FAD in vitro. Investigation into the vitamin $\mathrm{B}_{2}$ status in healthy people and geriatric patients. International Journal of Vitamin Research 40, 166-183.

Goodlad RA \& Wright NA (1990) Changes in intestinal cell proliferation, absorptive capacity and structure in young, adult, and old rats. Journal of Anatomy 173, 109-118.

Henning SJ \& Guerin DM (1981) Role of diet in the determination of jejunal sucrase activity in the weanling rat. Pediatric Research 15, 1068-1072.

Henning SJ, Helman TA \& Kretchmer N (1975) Studies on normal and precocious appearance of jejunal sucrase in suckling rats. Biology of the Neonate 26, 249-262.

Lanzkowsky P, Karayalcin G \& Miller F (1982) Disaccharidase levels in iron deficient rats at birth and during the nursing and postweaning periods: response to iron treatment. Pediatric Research 16, 318-323.

Olpin SE \& Bates CJ (1982a) Lipid metabolism in riboflavindeficient rats. 1. Effect of dietary lipids on riboflavin status and fatty acid profiles. British Journal of Nutrition 47, 577-588.

Olpin SE \& Bates CJ (1982b) Lipid metabolism in riboflavindeficient rats. 2. Mitochondrial fatty acid oxidation and the microsomal desaturation pathway. British Journal of Nutrition 47, 589-596.

Parsons HG \& Dias VC (1991) Intramitochondrial fatty acid metabolism riboflavin deficiency and energy production. Biochemical Cell Biology 69, 490-497.

Ponder B, Schmidt GH, Wilkinson MM, Wood MM, Monk M \& Reid A (1985) Derivation of mouse intestinal crypts from single progenitor cells. Nature 313, 689-691.

Potton CS \& Hendry JH (editors) (1985) The microcolony assay in mouse small intestine. In Cell Clones: Manual of Mammalian Cell Techniques, pp. 50-61. Edinburgh: Churchill-Livingstone.

Potten CS \& Loeffler M (1990) Stem cells: attributes, cycles, spirals, pitfalls, and uncertainties. Lessons for and from the crypt. Development 110, 1001-1020.

Powers HJ, Bates CJ \& Duerden JM (1983) Effects of riboflavin deficiency in rats on some aspects of iron metabolism. International Journal of Vitamin Research 53, 371-376.

Powers HJ, Bates CJ \& Lamb WH (1985) Haematological response to supplements of iron and riboflavin to pregnant and lactating women in rural Gambia. Human Nutrition: Clinical Nutrition 39C, 117-129.

Powers HJ, Weaver LT, Austin S, Wright AJA \& Fairweather-Tait SJ (1991) Riboflavin deficiency in the rat: effects on iron utilization and loss. British Journal of Nutrition 65, 487-496.

Thomson AM, Keelan M, Garg M \& Clandinin MT (1989) Evidence for critical period programming of intestinal transport function: variations in the dietary ratio of polyunsaturated to saturated fatty acids alters ontogeny of the small intestine. Biochimica et Biophysica Acta 1001, 302-315.

Tillotson JA \& Baker EM (1972) An enzymatic measurement of the riboflavin status of man. American Journal of Clinical Nutrition 25, 425-431.

Totafurno J, Bjerknes M \& Cheng H (1987) The crypt cycle. Crypt and villus production in the adult intestinal epithelium. Biophysical Journal 52, 2792-2794.

Williams EA, Powers HJ \& Rumsey RDE (1995) Morphological changes in the rat small intestine in response to riboflavin depletion. British Journal of Nutrition 73, 141-146.

Williams EA, Powers HJ \& Rumsey RDE (1996a) An investigation into the reversibility of the morphological and cytokinetic changes seen in the small intestine of riboflavin deficient rats. Gut 39, 220-225.

Williams EA, Rumsey RDE \& Powers HJ (1996b) Cytokinetic and structural responses of the rat small intestine to riboflavin depletion. British Journal of Nutrition 75, 315-324.

Wynford-Thomas D \& Williams ED (1986) Use of bromodeoxyuridine for cell kinetic studies in intact animals. Cell Tissue Kinetics 19, 179-182.

Younoszai MK \& Ranshaw J (1974) Gastrointestinal growth in normal male and female rats. Growth 38, 225-235. 